\title{
Cone Penetrometer
}

\section{INNOVATIVE TECHNOLOGY SUMMARY REPORT}

U.S. Department of Energy Sites: SRS, Hanford, SNL, Fernald, Pantex, Portsmouth; Department of Defense; other Federal and Commercial Sites

prepared for

\section{U.S. Department of Energy}

Office of Environmental Management

Office of Science and Technology

April 1996

ISTRIBUTION OF THIS DOCUMENT IS UNLIMTEE

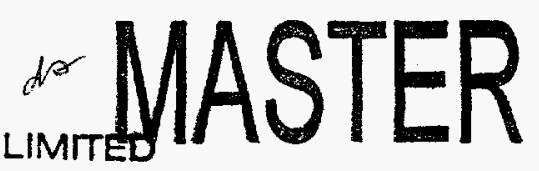




\section{DISCLAIMER}

Portions of this document may be illegible in electronic image products. Images are produced from the best available original document. 


\section{TABLE OF CONTENTS}

1 SUMMARY

page 1

2 TECHNOLOGY DESCRIPTION

page 4

3 PERFORMANCE

page 8

4 TECHNOLOGY APPLICABILITY \& ALTERNATIVES

page 11

5 Cost

page 12

6 REGULATORY/POLICY ISSUES

page 16

7 LESSONS LEARNED

page 17

\section{APPENDICES}

\section{A Additional Sensor Description}

B References 


\section{SUMMARY}

\section{Technology Description}

Cone penetrometer technology (CPT) provides cost-effective, real-time data for use in the characterization of the subsurface. Recent innovations in this baseline technology allow for improved access to the subsurface for environmental restoration applications. The technology has been improved by both industry and government agencies and is constantly advancing due to research efforts. The U.S. Department of Energy (DOE) Office of Science and Technology (formerly Technology Development) has contributed significantly to these efforts. This report focuses on the advancements made in conjunction with DOE's support but recognizes Department of Defense (DOD) and industry efforts.

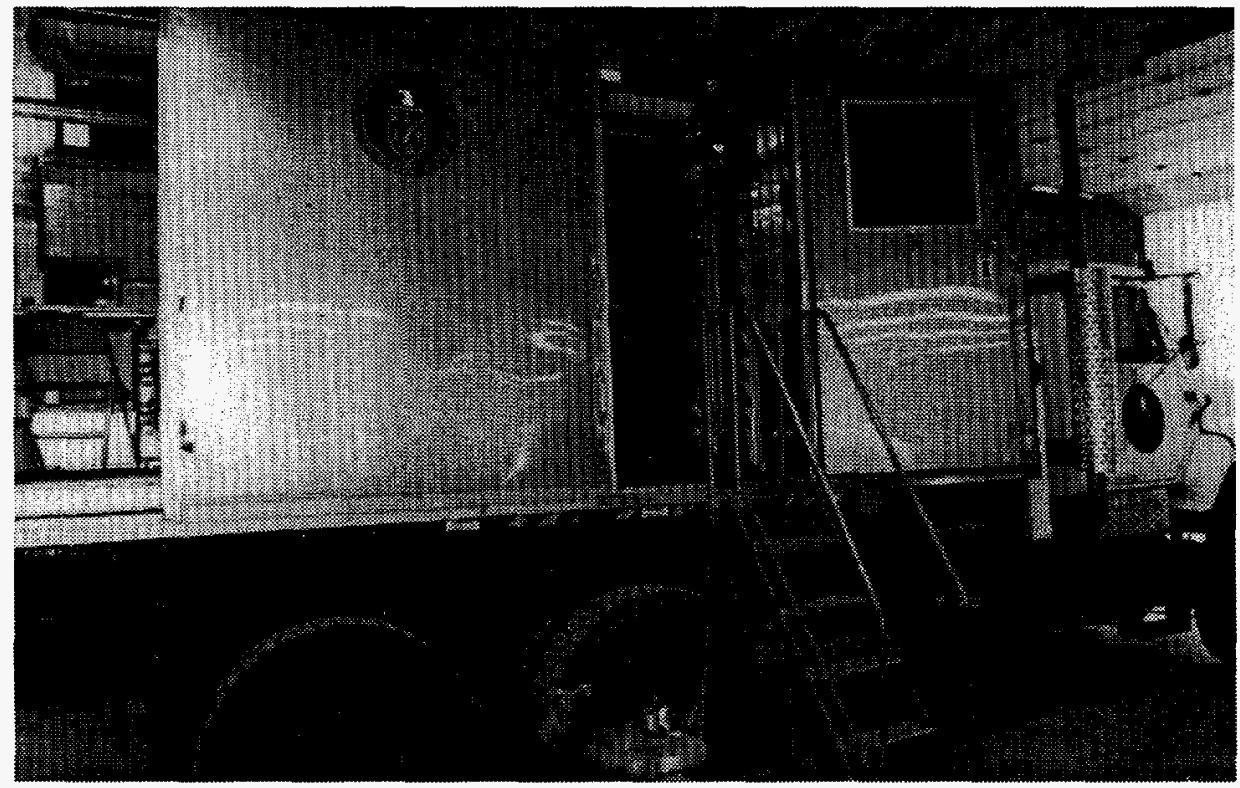

- Cone penetrometer technology (CPT):

- provides continuous, subsurface, screening-quality data (physical, electrical, and chemical measurements) to aid in site characterization;

- minimizes disturbance to the subsurface, as no drilling fluids are used and hole diameters are quite small (1-2") (this also minimizes migration of contaminants from shallower to deeper horizons during pushing);

- is relatively inexpensive when compared to drilling and sampling;

- offers the advantage of real-time data analysis so that push locations can be selected based upon the results of holes already pushed;

- can be adapted for new sensors to measure various types of chemical contaminants and other physical characteristics of the subsurface;

- can be used to install piezometers for soil vapor and ground water measurements;

- can be used to collect soil and water samples;

- is safer than conventional drilling because worker exposure is minimized due to faster subsurface access and generation of minimal amounts of waste;

- cannot be used at all sites, i.e. all lithologies; however, recent advances in technology have expanded the envelope of sites for which the technology is applicable;

- provides rapid, cost-effective assistance in the definition of contaminant plumes enabling more accurate placement of remediation systems and monitoring wells.

- The cone penetrometer consists of a steel cone that is hydraulically pushed into the ground while in situ measurements are continuously collected and transported to the surface for data interpretation and visualization.

- The hydraulics are housed in a vehicle that can provide ballast of up to 80,000 pounds. 
- New trucks developed for environmental applications separate the hydraulic system from data management to minimize worker exposure to contaminated rods.

- Penetration rates can be as high as $180 \pm 300$ feet per hour, but are typically 40 to 50 feet per hour. ASTM standards require 2 centimeters/second maximum push rate for data collection.

- Standard cone penetrometers collect stratigraphic information using sensors for cone tip pressure and sleeve friction. The ratio of the tip resistance to the sleeve friction provides information that can be used to classify soil type.

- Other sensors available include two-axis inclinometers, acoustic cone (for identification of soil type), temperature, $\mathrm{pH}$, radioactivity (gamma), and geophones for measurement of $\mathrm{P}$ (pressure) and $\mathrm{S}$ (shear) waves (surface to borehole seismic).

- Recent advances in sensor technology have expanded cone penetrometer capabilities to measurement of total petroleum hydrocarbons. Research is underway by the Navy, the Air Force, the Army, DOE, and industry to incorporate sensors for detection of other organics, metals, radioactivity, explosives, soil or waste moisture. The Navy and Air Force are working to upgrade system software and hardware.

- Other developments underway with DOE funding through the Morgantown Energy Technology Center, include addition of a vibratory assist device to allow penetration through hard zones (UTD, Inc.), subsurface imaging using CPT (ARA), implantation of and resistivity electrodes for tomographic interpretation (ARA), a position locating surveyor to assist with angled cone penetrometry (UTD, Inc.), a sonic-based push system based on ResonantSonic ${ }^{\text {SM }}$ technology (Water Development Corporation), integration of a fast gas chromatograph into the cone penetrometer system (ARA), and a fiberoptic heavy metals detection system (SEA, Inc.).

\section{Technology Status}

- The forerunner of CPT, sounding of soils, was developed in 1917, while the technology as we recognize it was introduced in 1934 in the Netherlands. Actual electrical measurement sensors were not developed until 1948 and not widely used until the 1960s. Early applications of the technology were for geotechnical investigations.

- In the 1980s, the cone penetrometer was commonly used for geotechnical applications in certain areas of the U.S. (at least a dozen companies routinely provided the technology) and its use for environmental site investigations was tested at a number of locations. In the late 1980s research to develop other sensors for deployment on the cone penetrometer was initiated.

- In 1985, the U.S. Army Corps of Engineers Waterway Experiment Station (WES) proposed the use of the cone penetrometer for hazardous waste site characterization (SCAPS: site characterization and analysis penetrometer system) and in 1987 the Navy introduced a sensor for detection of petroleum hydrocarbons (laser induced fluorescence: LIF). In 1989, the Army, Navy and Air Force, along with the DOE and the Environmental Protection Agency (EPA) began a coordinated program to integrate these two technologies and develop other sensors for contaminants. Another sensor for petroleum hydrocarbons (the wavelength tunable high energy pulsed ultraviolet laser developed by North Dakota State University in conjunction with the Air Force, (now known as ROST ${ }^{\mathrm{TM}}$ ) has been successfully demonstrated.

- In 1990, DOE also began working with industry, Applied Research Associates (ARA), to advance the technology for environmental applications. This joint industry-government partnership has resulted in 1) the development of a heavy-weight cone penetrometer for applications at difficult drilling sites 2) the demonstration of a chlorinated solvent sensor/cone penetrometer system, and (3) the development of a cone penetrometer to investigate high level radioactive wastes in underground storage tanks.

- The original LIF (monochromatic) sensor has been licensed by the Army to two companies (ARA and Hogentogler). ARA is marketing the LIF system. A Cooperative Research and Development Agreement focusing on the wavelength tunable sensor system has been signed between the Air Force, Navy, and Loral. This system is commercially available from Loral as the ROST $^{\mathrm{TM}}$ system (Rapid Optical Screening Tool).

- The SCAPS-LIF and the ROST ${ }^{\mathrm{TM}}$ technologies have been demonstrated at numerous sites, have been shown to be effective tools for screening of sites for petroleum hydrocarbons, and are now undergoing a number of regulatory acceptance efforts:

- The Navy is collaborating with the state of California (Cal-EPA) to obtain regulatory technology certification. Cal-EPA has issued a notice for public comment as of March 1996. 


\section{SUMMARY}

\section{continued}

- The technology developers are also working with the Western Governors Association Demonstration of On-site Innovative Technologies (DOIT) Committee to promote interstate cooperation on innovative technologies and with the US EPA Center for Site Characterization to validate the technology (demos at Port Hueneme and Sandia National Laboratory).

- Lastly, the Navy is working with eastern regulators to extend the types of sites for which the technology is validated.

- The heavy-weight cone penetrometer has been successfully demonstrated at a number of sites (Hanford, Fairchild AFB and the central U.S.) and has been shown to be a cost-effective tool for site characterization at sites described as difficult to drill.

- Recent developments in CPT are now commercially available (more than 10 companies provide basic services). Refinements in the technology are quickly being developed and the technology is rapidly being deployed at numerous sites.

\section{CONTACTS}

\section{Technical}

Candace Rose, Argonne National Laboratory, 708-252-3499

Carol Eddy Dilek, Savannah River Technology Center, 803-725-2418

Neil Higgins/Jimmie Bratton, ARA, 505-881-8074 or Jim Shinn, ARA, 802-763-8348

Steve Lieberman and Tom Hampton, NCCOSC (NRaD), 619-553-2778/1172

John Ballard, USAE Waterways Experiment Station, 601-634-2446

Specific sensor contacts are listed in Section 2.

\section{Management}

Eric Lightner, DOE, 301-903-7935

\section{Licensing Information}

Licensing information can be obtained from the contacts listed in the specific sensor descriptions in Section 2. 


\section{SECTION 2}

\section{TECHNOLOGY DESCRIPTION}

\section{Overall System Description}

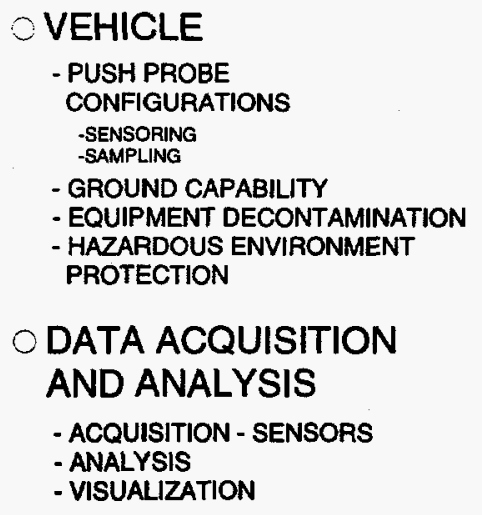

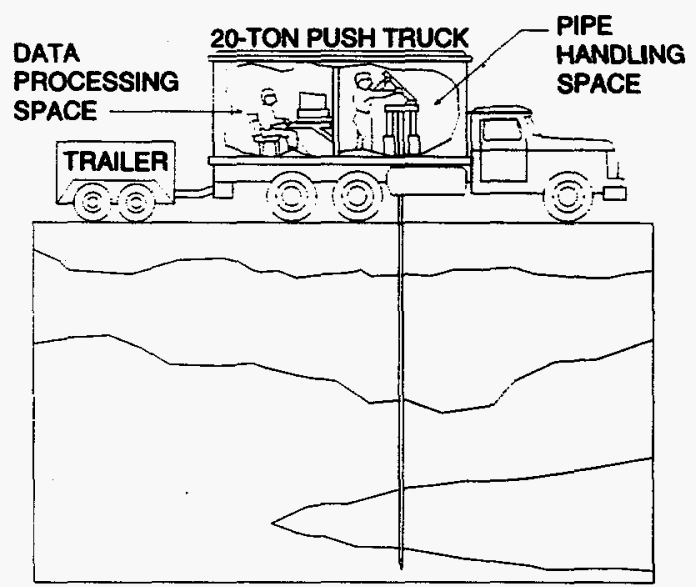

- The cone penetrometer typically consists of 1) an enclosed 20-40 ton truck equipped with vertical hydraulic rams that are used to force a sensor probe into the ground, 2) a data acquisition, processing, and data storage computer system, and 3) electronic signal processing equipment.

- A typical description of an advanced cone penetrometer system, such as the SCAPS, to be used as a tool for environmental site investigations follows. Other systems have been built with slightly different specifications. Some probes, such as the standard sleeve friction and tip resistance, electrical resistivity, $\mathrm{pH}$, temperature, ground penetrating radar, and seismic are not described below.

- The inside of the truck can be divided into two temperature-controlled compartments: a hydraulic ram/rod handling room and a data acquisition/processing room. In addition, the truck is equipped with a specially designed steam cleaning system to remove soil and contaminants from the push rods as they are withdrawn from the ground.

- A trailer-mounted grout pumping system has been developed for proper hole abandonment. The trailer-mounted grouting system has been incorporated into the probe to allow grouting of the hole as the probe is withdrawn, thus minimizing vertical subsurface cross-contamination.

Vehicle Description

Weight:

Length:

Rear axles are $35,000 \mathrm{lb}$ and front axles are $12,000 \mathrm{lb}$. with a total weight of $47,000 \mathrm{lb}$.

Width: $34.5 \mathrm{ft}$

Van Body:

$8 \mathrm{ft}, 6$ in

Two separate compartments, each $7.5 \mathrm{ft}$ wide by $9 \mathrm{ft}$ long by $7 \mathrm{ft}$ high, stainless steel skin inside and out.

Hydraulic System Description

Rams: $\quad$ Twin hydraulic, 48-in stroke

Clamp: Hydraulic with intensifier

Guide Tube: $\quad$ Retractable, with safety clamp

Force Output: $\quad 40,000-1 b$ push, 60,000-lb retract @2000 psi

Speed:

$2 \mathrm{~cm} / \mathrm{sec}$ (regulated) during push and up to $12 \mathrm{~cm} / \mathrm{sec}$ retract

\section{Data Acquisition/Processing}

Signal Conditioning: 8 Channel

Data Processing: Two Hewlett Packard Vectra computers, $25 \mathrm{MHz}$, with data translation AVD boards 


\section{Samplers}

Sampling probes have been developed to collect continuous or discrete samples from different media.

Soil:

Swedish MOSTAP ${ }^{\mathrm{TM}}$, Gouda ${ }^{\mathrm{TM}}$, Hogentogler

Water:

QED HydroPunch ${ }^{\mathrm{TM}}$, ARA water sampling system, BAT ${ }^{\mathrm{TM}}$, SRS ConeSipper ${ }^{\otimes}$, and others

Soil gas:

Vadose Zone Vapor (VZV) Probe and others

Below is a schematic of a ground water sampler.

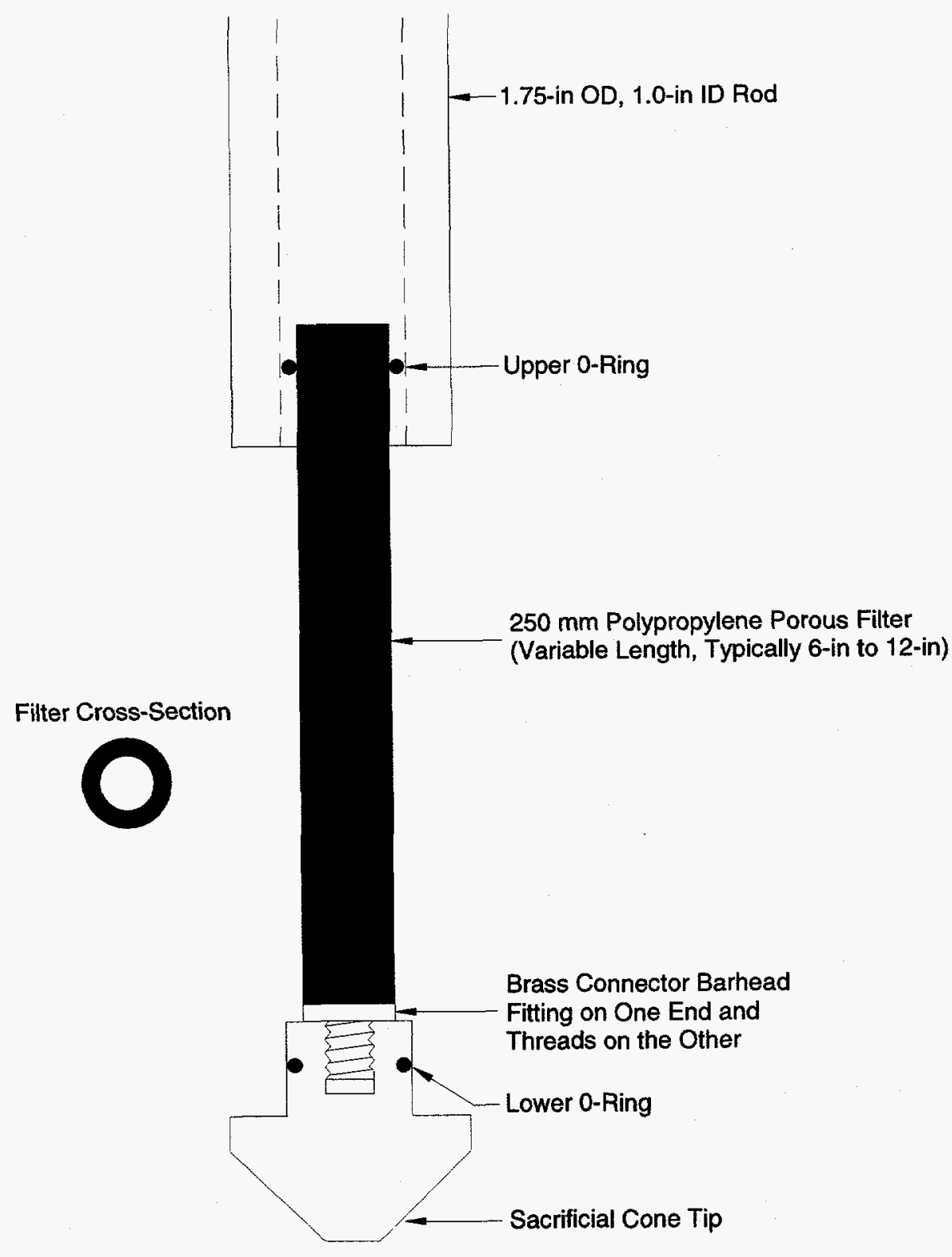


SCAPS LIF Probe (NRaD, Stephen Lieberman, 619-553-2778)

Laser:

PTI 2300 Nitrogen laser

$337 \mathrm{~nm}$ wavelength (monochromatic)

1000 micro Joule output energy

Detector:

EG\&G 1421 Photo diode array (PDA)

EG\&G 1460 Optical Multi-channel Analyzer (OMA)

This sensor provides screening information on the content of petroleum hydrocarbons in the subsurface. The LIF data are acquired at $8 \mathrm{~cm}$ intervals during a CPT push. This sensor is currently available in Army, Navy, and DOE trucks and has been licensed by ARA. ARA has developed the Fuel Fluorescence Detector (FFD), based on the Navy licensed technology.

Modifications include a $254 \mathrm{~nm}$ downhole light source with an uphole photomultiplier tube. The LIF data are recorded and summarized for on screen display during the penetration test. Two numbers that represent the maximum intensity of the fluorescence and the area under the intensity curve between 350 and $472 \mathrm{~nm}$ are presented. Factors that can contribute to the LIF signal include: contaminant concentration, soil type, mineralogy, moisture content, and other site conditions.

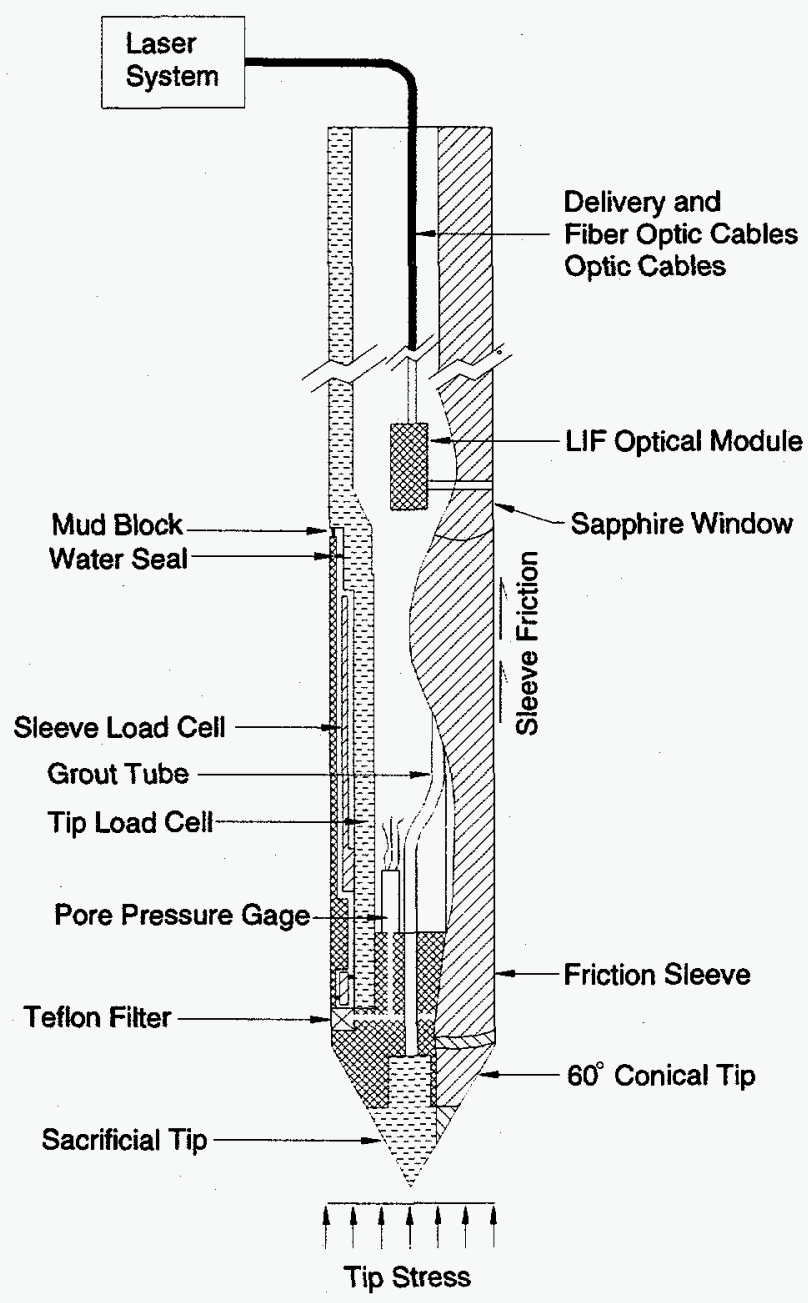


ROST ${ }^{\mathrm{TM}}$ Probe (Available commercially from Loral, 612-456-4000)

Laser: Wavelength tunable high energy pulsed UV light

Detector: Photo multiplier tube analyzer

This sensor, originally developed by a professor (Greg Gillespie) at North Dakota State University with funding from DOD, also can be used to screen the subsurface for petroleum hydrocarbons.

Time Domain Reflectometry (TDR) Probe [Sandia National Laboratory (SNL), Robert Knowlton, 505-844-8533] This sensor uses an electromagnetic pulse, generated by a Textronix 1502B Cable Tester, to continuously measure the dielectric constant of the soil. The dielectric constant is then used to calculate volumetric soil moisture content. ARA has developed a soil moisture sensor (SMR) based on similar principles, measurement of dielectric constant while also measuring resistivity.

Fiber Optic RH Probe (SNL, Robert Knowlton, 505-844-8533)

This sensor, developed by Sandia in cooperation with GEOCENTERS, Inc., measures relative humidity, which can be used to calculate capillary pore pressure in unsaturated soils. It is based upon an optrode that consists of a porous polymer chemical sensor between two optical fibers. Light is introduced at two different wavelengths. Optical absorption and transmission are measured.

\section{Electrochemical Sensors (Under development at WES with Transducer Research)}

Detector: Gold-sensing and platinum electrodes

Other features: External pyrolyzing system to create vapors for analysis and pneumatic system to transport vapors to sensors.

This sensor has been demonstrated to detect explosives such as TNT in soils.

Radiation Probes (Under development at WES, ARA, and Fugro)

Active and passive systems are either developed or under development; they have varying sensitivities and can be used to detect radionuclides or for soil density. WES is developing a system with a Sodium Iodide detector that measures gross gamma while penetrating and spectral data at selected depths. A schematic of a radiation probe is shown in Appendix A.

\section{SCAPS Grout System}

Tank Capacity: $\quad 300$-gal

Suspension: Torsion bar, twin axles

Load Capacity: $\quad$ 7500-lb

Frame: Heavy wall 4-in square tubing

Auxiliary

Equipment:

Chem-grout processing cavity positive displacement grout pump, computer controlled Four hydraulic jacks, independently controlled, two each

ResonantSonic $^{\text {SM }}$ Cone Penetrometer (Available from Water Development Corporation, Don Moak, 509-377-3977) Cone penetrometer type rods $(1.75 \mathrm{inch})$ were adapted to use with the ResonantSonic ${ }^{\mathrm{SM}}$ drilling rig at Hanford to allow better penetration through geologically difficult drilling materials. 


\section{SECTION 3}

\section{PERFORMANCE}

\section{Demonstration Overview}

Cone penetrometer systems have been demonstrated at a number of DOE, DOD, other government, and commercial sites across the U.S. A discussion of all demonstrations and applications of the technology is impossible within the confines of this report. This discussion focuses on a number of demonstrations conducted with support from the DOE Office of Science \& Technology program.

SCAPS was first demonstrated at a number of DOD sites across the U.S. (first at the Jacksonville Naval Air Station in 1990) where site lithology and contaminant chemistry data were collected. Little was known about the extent and level of contamination at these sites and no verification of data quality was attempted. In 1991 and 1992 the first SCAPS demonstration was conducted at three well characterized sites where core samples had been previously collected. No verification was attempted on specific samples, but overall knowledge of the contaminant plumes supported results collected by SCAPS.

- The 1991 Savannah River Site (SRS) demonstration at the Central Shops Facility showed that the SCAPS-LIF could detect and delineate hydrocarbons in soil as a site screening technology, but the detection limits were not equivalent to standard analytical laboratory limits. SCAPS was utilized to develop a three-dimensional volumetric image of the contaminant plume that correlated well with that prepared using core samples analyzed in the laboratory. However, no specific verification was conducted.

- The 1991-1993 SRS SCAPS demonstrations also included testing of a prototype "optrode" fiber-optic sensor designed to measure trichloroethylene (TCE) in soils and/or ground water. Also demonstrated was implantation of a soil gas sampler, called the Terratrog, developed by the Illinois Institute of Technology Research Institute. A later demonstration included a Raman spectroscopy system to detect TCE developed by EIC Laboratories.

- WES was contracted by DOE to build a SCAPS vehicle. This vehicle has been, and continues to be, available to various DOE sites. ARA has been awarded a contract to operate the system. Since 1994, the DOE SCAPS vehicle has been demonstrated at a number of sites, including SRS, Fernald, Portsmouth, Pantex, Beckley West Virginia, and Dover Air Force Base.

- Since 1993 the Navy, Army, Air Force, EPA and DOE have continued efforts to demonstrate the existing technology at a number of sites to verify its performance within an envelope of differing geology/hydrology and differing types of contaminants. They have continued to make modifications to existing equipment and to develop new sensors. And they have aggressive programs to ensure technology commercialization and regulatory acceptance.

- Commercial applications of the technology have grown significantly. For example, Loral used the ROST ${ }^{\mathrm{TM}}$ system at more than thirty sites in less than one year after its introduction.

- The technology (with ROSTM \& LIF sensors) was demonstrated under the EPA's SITE program at three sites within Region 7. 


\section{Heavy-Weight Direct Push Technology}

The DOE Hanford Site is characterized as difficult to drill (i.e. soils consist of gravels and cobbles). After an initial demonstration of CPT using the standard 20-ton rig at Hanford in 1991, efforts were directed towards development of a heavy-weight cone penetrometer that could be utilized at Hanford and other difficult drilling sites. Modifications included upgrading of the thrusting capacity and reinforcement of tools to withstand the forces required for penetration.

In 1992, using a new 30-ton cone penetrometer rig, depths ranged from 1.82 to $44.8 \mathrm{~m}$ ( 6 to $147-\mathrm{ft}$ ) with a site average of $19 \mathrm{~m}$ $(62.5-\mathrm{ft})$. This average is more than three times the $6.2 \mathrm{~m}(20.5-\mathrm{ft})$ average for earlier tests conducted using the standard 20 -ton rig. CPT pushes were conducted in 1992 directly adjacent to the locations where pushes were conducted in 1991. The 30-ton rig was able to consistently push beyond the point of refusal in the 20-ton rig and reach the desired depth. Penetration forces during this testing typically reached above the standard cone penetrometer $18,143-\mathrm{kg}(40,000-\mathrm{lb})$ limit within the upper $6.2 \mathrm{~m}(20-\mathrm{ft})$. The modified (heavy 30-ton) CPT was able to penetrate layers where refusal was met with the 20-ton using an additional $11,363-\mathrm{kg}(25,000-\mathrm{lb})$ force. A typical plot of push force vs. depth is shown below to demonstrate the advantage of using the heavier CPT rig (30-ton).

The heavy weight cone penetrometer was also demonstrated at Fairchild Air Force Base in Washington state in 1993.

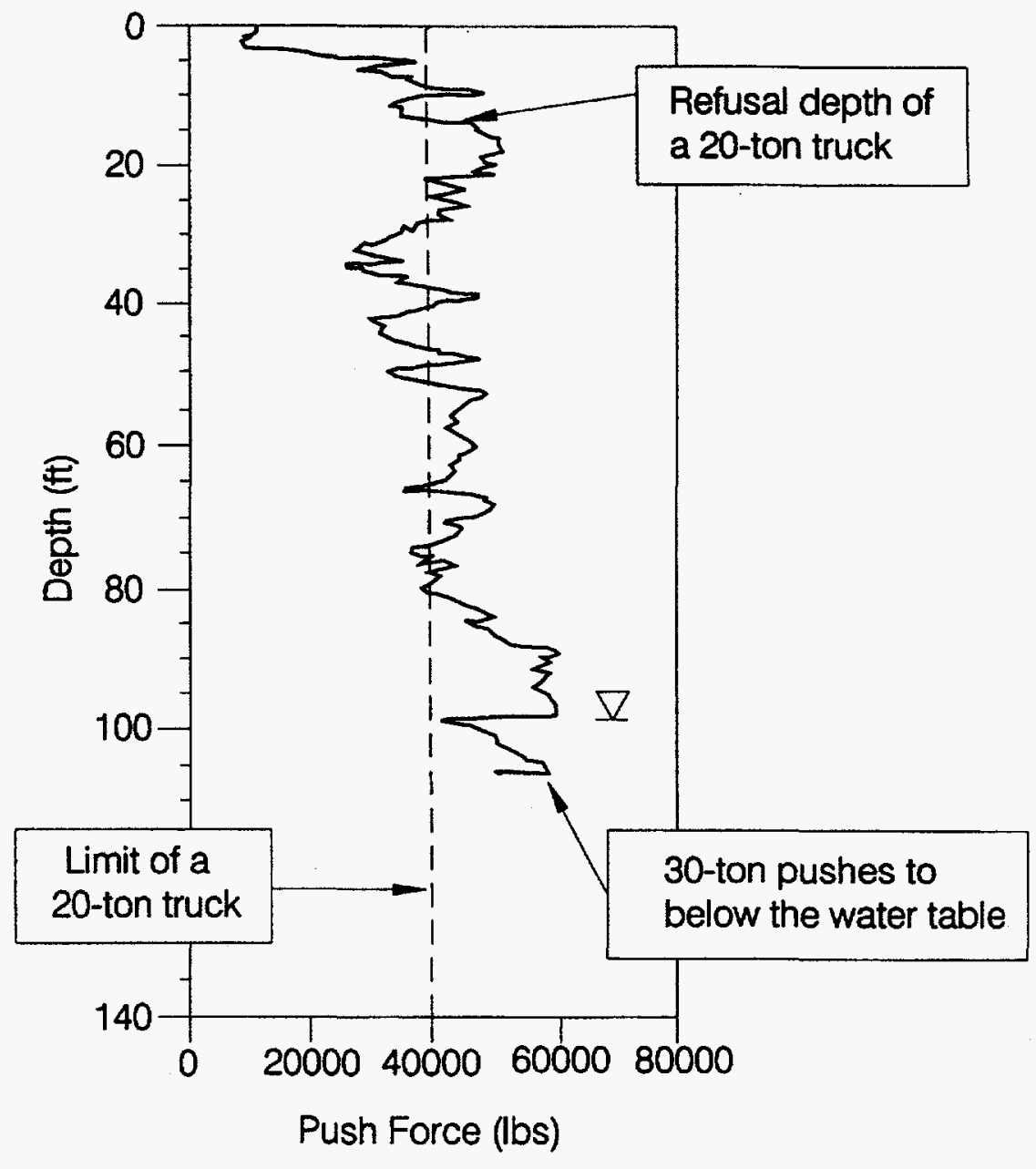




\section{LIF Sensor}

A trial of the SCAPS laser system was conducted at Hill Air Force Base. During the project 30 LIF CPT tests were conducted. Several soil samples were also collected and are being analyzed in the laboratory for comparison to the LIF signal. The system has been demonstrated at more than ten other sites. Results indicate that the sensor produces screening level data (i.e. low, medium, high zones of contamination) and qualitatively identified changes in contaminant type. At the EPA SITE demonstration, total petroleum hydrocarbon concentrations as low as $60 \mathrm{ppm}$ and volatile petroleum hydrocarbons as low as $19 \mathrm{ppm}$ were identified.

An example of LIF data from three locations at a single site is shown below.
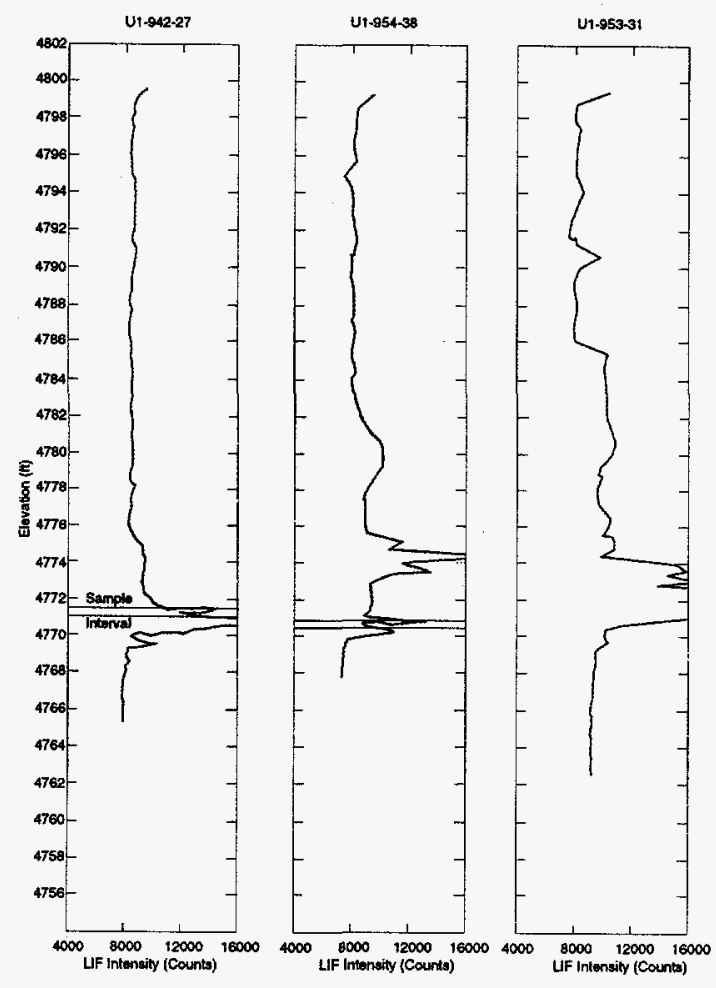

The sensor has been demonstrated as part of the EPA's Consortium for Site Characterization at Port Hueneme in California and at SNL in Albuquerque New Mexico. SNL has prepared a report documenting the results of these demonstrations. A number of other demonstrations using SCAPS-LIF have been conducted across the country. ARA's FFD sensor has been demonstrated to detect contaminants as low as 80 ppm in sands.

\section{Time Domain Reflectometry (TDR) and Relative Humidity (RH) Sensors}

SNL and ARA demonstrated these two sensors, one detecting soil moisture and the other for capillary pore pressure measurement, in Vermont and then in Albuquerque New Mexico at an infiltration test site. In Albuquerque, pushes were conducted to depths of 8 to 14 meters. The TDR probe demonstrated real-time, continuous, excellent-quality data. The TDR probe has been shown to provide better accuracy than can be obtained with neutron and capacitance probes and reflects details in lithology that cannot be detected with the standard cone penetration test using sleeve friction and tip resistance. The RH sensor can be used in the present configuration for point measurements; response time is not sufficient to collect continuous, real-time data. The sensor had difficulty making measurements in wet soils and in clay-rich soils (the housing was prone to plugging), but worked well in the arid southwestern soils at SNL.

\section{Explosives Sensor}

WES first demonstrated an electrochemical sensor system to detect explosives (TNT) during September 1994 at the Louisiana Army Ammunition Plant. Explosives were detected by the sensor at various depths in unsaturated soils and then were confirmed with soil samples analyzed in the laboratory. Both high sensitivity and a reasonably broad dynamic range were achieved, but a number of areas requiring improvement were also identified. 


\section{Technology Applicability}

\section{Technology Applicability}

- The optimum application of CPT is at sites requiring geological, hydrological, and geochemical characterization where the subsurface can be penetrated using forces up to 40,000 pounds. Sites that typically can be characterized with CPT contain surficial unconsolidated sediments (except those characterized as difficult to drill, i.e. where large boulders or cemented layers exist).

- CPT has been applied at sites as deep as 300 feet, but is generally applied to depths up to 150 feet.

- CPT's best application is as a screening tool to provide initial site characterization data, which are confirmed by collecting samples that are then analyzed in the laboratory.

- Sites that contain petroleum hydrocarbon contamination can be screened using either the LIF or ROST ${ }^{T M}$ sensors, thus providing rapid characterization of the subsurface contaminant plume.

- Data collected from CPT sensors can be used to reduce the number of monitoring wells required during site characterization investigations by collecting subsurface soil, soil gas, ground water and various chemical and geophysical readings.

- CPT allows for better selection of locations for installation of monitoring wells because a greater density of characterization samples can be collected for the same or less cost.

- CPT can be used to place monitoring devices in the subsurface.

- Future sensor development may allow in-situ analysis of additional chemical contaminants or physical characteristics.

\section{Alternative Technologies}

- The baseline technology against which CPT is compared is standard drilling and sampling. Different locations across the country use different technologies for drilling into the subsurface. One comparison of the CPT against cable tool drilling, as is typically used at the DOE Hanford site, is presented in the cost section. Comparison of the CPT to the standard drilling technology must be done for each type of drilling.

- Two direct-push alternatives are described below. Others exist.

- Geoprobe - alternative light weight direct-push sampling device

- Maximum depth in ideal geologic conditions is $100-\mathrm{ft}$

- Data includes soil conductivity, soil and shallow ground water sample collection

- Angle-push capability

- Enviro-Core - alternative light-weight direct-push sampling device

- Uses a combination of percussion, hydraulic, and vibratory push technology

- Maximum depths in ideal geologic conditions are 50-ft

- Obtains continuous soil core; therefore some wastes are produced

- Data include soil vapor, shallow ground water sample collection, and piezo-well installation

- Self-grouting capabilities

- Angle-push capability 


\section{SECTION 5}

\section{COST}

\section{Introduction}

Information in this section was prepared from data provided by the Volatile Organic Compounds (VOCs) in Arid Soils and Ground Water Integrated Demonstration and the VOCs in Non-arid Soils and Ground Water Integrated Demonstration to the Los Alamos National Laboratory (LANL), tasked to perform cost analyses as an independent team for the DOE Office of Environmental Management Office of Science \& Technology (EM-50). LANL performed two separate cost analyses efforts, one focused on CPT use at Hanford (comparing CPT to cable tool drilling) and one focused on CPT use at SRS or similar sites (comparing CPT to auger or mud rotary drilling).

- The LANL cost analyses were not meant as comprehensive cost estimates but were conducted to evaluate the costs of the innovative technology against a baseline technology.

- CPT is expected to continue to develop as new sensors are designed. These efforts will affect the cost estimates in both the baseline and the CPT application.

- CPT is expected to enhance the standard monitoring well not replace it; therefore methods of placement of the monitoring wells may change the variables used in the estimates.

\section{Cost Comparisons}

The baseline technology being used for this cost comparison was the drilling and installation of monitoring wells with the cabletool technology, typically used at the DOE Hanford Site. The innovative technology and baseline technology were looked at under 4 different scenarios. The first scenario is the only direct comparison of CPT with cable tool drilling technology. The other three scenarios look at cost savings incurred by combining CPT with drilling and installation of standard monitoring wells.

\section{- SCENARIO 1: Installation of a 50-foot Soil Vapor Monitoring Well}

The cable-tool monitoring well installation required collection of core samples to be chemically analyzed in order to determine the slotted liner casing location. The innovative technology application requires two cone penetrometer pushes to determine and place the equivalent soil vapor sampling well. The first to measure lithology, VOC contamination, soil structure, etc. The second to take the soil sample and prepare the well for placement of the Teflon sampling tube.

\begin{tabular}{lrc} 
& Cable Tool & Cone Penetrometer \\
\hline Installation & $\$ 20,764$ & $\$ 2,670$ \\
\hline Waste Disposal & $\$ 700$ & $\$ 0$ \\
\hline Total & $\$ 21,463$ & $\$ 2,670$ \\
\hline
\end{tabular}


- SCENARIO 2: Using CPT to Avoid Drilling and Installation of Non-useful Monitoring Wells

Under normal installation procedures approximately 25 to 65 percent of wells installed do not produce useful information. This scenario looks at use of the CPT to reduce the number of these wells by performing pre-placement pushes to identify the most advantageous locations for monitoring wells. The assumption made for this comparison is that (1) 20 wells drilled to a depth of 100 feet would be the baseline, (2) some percentage of these wells are not productive, and (3) the use of the 40 cone penetrometer pushes can avoid the non-productive wells. Data below show that the use of CPT and thus fewer monitoring wells represents a $45 \%$ savings in cost. Because, it is not really known how many wells can be avoided through the use of CPT, the graph below shows that if $15 \%$ or more of the wells are avoided, the use of CPT results in overall cost savings.

\begin{tabular}{lcrc}
\hline Cable Tool & Cable Tool & Cone Penetrometer & Cone Penetrometer \\
\hline Installation & $\$ 867,529$ & Installation & $\$ 433,764$ \\
\hline Monitoring & $\$ 142,440$ & Single CPT Push & $\$ 2,372$ \\
\hline Abandonment & $\$ 31,470$ & All Penetrometer Pushes & $\$ 142,302$ \\
\hline Total & $\$ 1,041,439$ & Total & $\$ 576,066$ \\
\hline
\end{tabular}

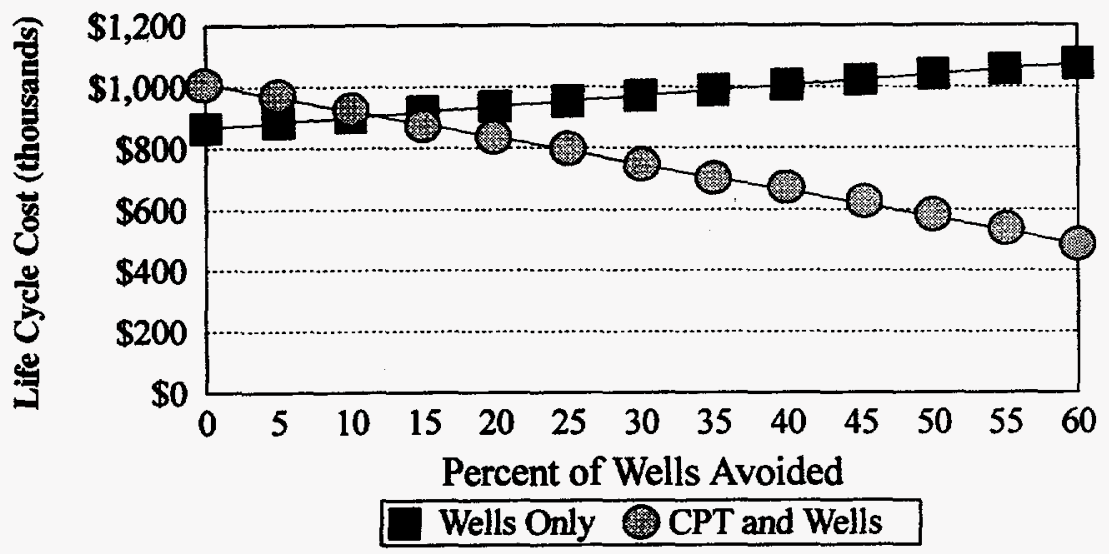

Scenario 2: Standard 20 well site dollars compared to wells avoided using 40 CPT pushes. 
- SCENARIO 3: Determining the Effectiveness of CPT to Perform the Same Initial Screening as the Standard Baseline of 4 Monitoring Wells Placed on a Site to Establish Contamination Levels.

The comparison shows the number of cone penetrometer pushes for initial site investigations possible equivalent to the cost of the standard 4 monitoring wells. Fifty-one locations are characterized with the cone penetrometer to a depth of 100 feet; each location has two pushes. The number of pushes that could be completed would be greater if the depth were less. For example, if the depth of investigation were fifty feet, approximately 65 locations could be investigated.

\begin{tabular}{lcrc}
\hline Cable Tool & Cable Tool & \multicolumn{1}{c}{ Cone Penetrometer } & Cone Penetrometer \\
\hline Installation & $\$ 173,506$ & Installation & $\$ 0$ \\
\hline Monitoring & $\$ 56,976$ & Single CPT Push & $\$ 2,372$ \\
\hline Abandonment & $\$ 12,588$ & All Penetrometer Pushes & $\$ 241,913$ \\
\hline Total & $\$ 243,070$ & Total & $\$ 241,913$ \\
\hline
\end{tabular}

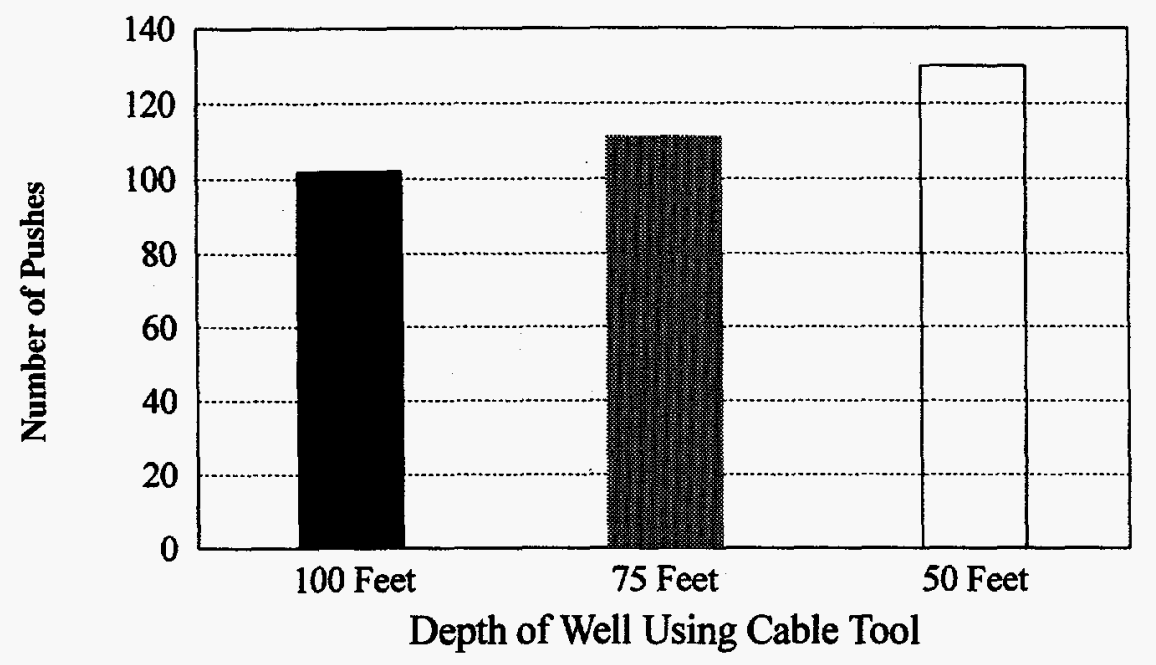

Scenario 3: Number of CPT Pushes Equivalent in Cost to Four Monitoring Wells. 
- SCENARIO 4: Using the CPT to Avoid Non-useful Monitoring Wells in a Radiological Area.

This scenerio assumes the same parameters as those provided in Scenario 2 with the exception that the area is radioactively contaminated. A factor of 4 is added to the Scenario 2 baseline to account for additional costs associated with dress-out and disposal of waste when operating in a radiological area. Only a factor of 1.5 is needed for the CPT efforts because the CPT does not produce any drilling waste requiring disposal and only one worker will be required to dress out for the CPT decontamination whereas 4 are required with the drill rig. It should be noted that at the time of the LANL report there was no known use of the CPT in a radiological area. Therefore the cost comparison is speculative and care should be used in evaluating these numbers.

\begin{tabular}{lcrc}
\hline Cable Tool & Cable Tool & Cone Penetrometer & Cone Penetrometer \\
\hline Installation & $\$ 3,542,115$ & Installation & $\$ 1,771,057$ \\
\hline Monitoring & $\$ 194,160$ & Single CPT Push & $\$ 7,430$ \\
\hline Abandonment & $\$ 31,470$ & All Penetrometer Pushes & $\$ 267,453$ \\
\hline Total & $\$ 3,767,745$ & Total & $\$ 2,038,510$ \\
\hline
\end{tabular}

Because, it is not really known how many wells can be avoided through the use of the CPT, the graph below shows that if less than $10 \%$ or more of the wells are avoided, the use of CPT results in overall cost savings.

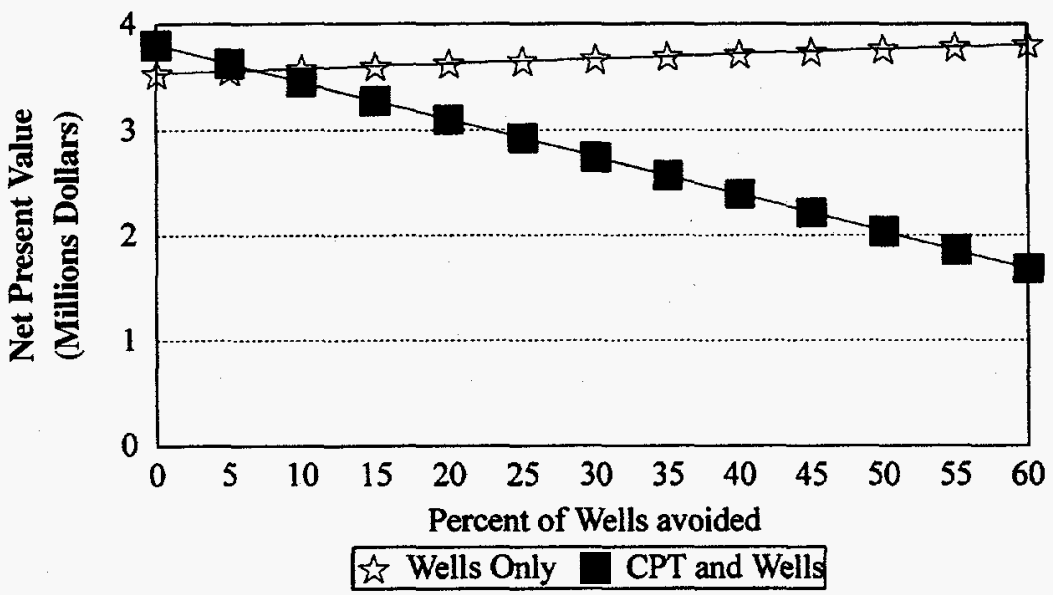

Scenario 4: Standard 20 well site dollars compared to wells avoided using 40 CPT pushes in a radiological area.

Cost analyses were also conducted using drilling cost data (auger and mud rotary) from the SRS (Schroeder et al., 1991). Four similar scenarios were built. These analyses showed similar results, but lower cost savings ( 30 to $50 \%$ ) because well drilling costs at SRS are less than at Hanford.

\section{Cost Results}

- Cost savings of 30 to more than $60 \%$ can be obtained by using CPT to first screen a site and then reduce the number of monitoring wells required by $50 \%$. Optimization of the monitoring wells locations is the key to this conclusion. It does not take into account cost savings that result because laboratory analyses are not initially performed.

- Using CPT to install a 50-ft. vadose zone monitoring well will cost only $11 \%$ of the cable-tool drilling costs.

- Characterization of site geology can be accomplished with either CPT or cable tool, given appropriate controls using core. CPT can characterize 13 times more locations than can standard cable tool core holes.

- Use of CPT in radiological areas will reduce worker exposure, time, and cost. This market niche is in its infancy but has great potential. 


\section{REGULATORY/POLICY ISSUES}

\section{Regulatory Considerations}

- Normal drilling/sampling activities require that investigative derived wastes [IDW] (drilling fluids, cuttings, and equipment decontamination fluids) be handled according to RCRA. CPT generates only minimal IDW (decontamination fluid only).

- No special permits are required for the operation of a cone penetrometer. Regulatory approval is typically handled as in standard drilling where a drilling plan is submitted to the appropriate regulatory agency for their approval prior to initiation of field activities.

- OSHA requirements for cone penetrometer operation should be less stringent than standard drilling techniques (cone penetrometer produces less noise, no waste, no rotary parts, no hammer drive mechanisms, etc.).

\section{Technology Description}

- Much of CPT data can be collected in real-time and then can be used for on-site decision making by the investigators as well as regulatory officials.

- Sealing and grouting of penetrometer holes can be done as the piezocone is removed from the ground thus ensuring the hole is sealed from the depth of penetration to the surface, thus minimizing the potential for migration of contaminants from shallower to deeper horizons. The smaller diameter of the cone penetrometer hole also minimizes the potential for contaminant migration.

- Rods are pressure steam cleaned as they are retracted, producing a minimal amount of decontamination water at each site.

\section{Safety, Risks, Benefits, and Community Reaction}

\section{Worker Safety}

- The operation crew's exposure to hazardous materials is minimal as the rods are steam cleaned before they enter the push compartment where some of the crew is located.

- A truck with a two-compartment system that allows for data acquisition personnel to be totally isolated from any hazardous materials entering the vehicle through the push compartment can be used. However, most sites require only Level D protection.

- Each of the two compartments in the truck have separate air quality control systems.

- The potential exposure of site personnel to hazardous materials is greatly reduced because no wastes are brought to the surface. This also reduces the amount of hazardous material that must be controlled and discarded.

\section{Community Safety}

- CPT is less intrusive than traditional drilling techniques and data can be gathered from areas inaccessible to drill rigs.

- No drill cuttings or drilling fluids are produced during operations, reducing the potential exposure to the surrounding community.

- Data can be collected in a more rapid manner, reducing the time necessary for the site characterization investigation.

\section{Environmental Impacts}

- Environmental impacts are generally less than with traditional drilling operations because:

- no drill cuttings or drilling fluids are produced during operation;

- the penetrometer holes are smaller in diameter than most drill rods and can be sealed during retraction of the penetrometer rods;

- the entire system can be decontaminated at the surface with a minimal amount of fluid.

\section{Socioeconomic Impacts and Community Perception}

- CPT will have a minimal impact on the labor force and the economy of the region.

- The general public has limited familiarity with CPT, but would be expected to support it as an improvement over baseline technology, as it is less intrusive than drilling. 


\section{LESSONS LEARNED}

\section{Implementation Considerations}

- When considering the selection of CPT at a particular site, the technology should be compared to standard drilling technology typically used at the site .

- Comparisons can be made in terms of reduction of waste materials, time required to characterize the site, the likelihood that the cone penetrometer can penetrate to the desired depths, the type of data required for characterization and whether CPT provides such, improvement in worker safety issues, and overall costs for characterization.

- The site manager must work with the regulators to assure acceptance of the data collected.

- CPT does not replace sampling and analysis for site characterization but provides a tool for rapid field screening during initial site characterization.

\section{Technology Limitations/Needs for Future Development}

- CPT is dependent on appropriate geologic conditions to assure penetration to the required depths. Developments such as integration of cone technology with sonic technology to produce resonant sonic cone penetrometry are underway. Other developments may provide the opportunity for extending the number of sites to which the technology can be applied successfully.

- Sensor development is still in its infancy. Many sensors are needed to better characterize sites, but they are not yet available.

\section{Technology Selection Considerations}

- Specific job requirements and site conditions will dictate the application of the best technology for investigation at a particular site. Innovative technologies, such as CPT, should be considered within the toolbox of available technologies. Systems such as CPT provide great potential because of their capability to provide multiple types of data during a single investigation.

- The SCAPS, and technology associated with its operation, is expected to provide an improved, rapid, and cost-effective tool to be used in site characterization investigations at hazardous waste sites. 


\section{APPENDIX A}

\section{ADDITIONAL SENSOR DESCRIPTION}

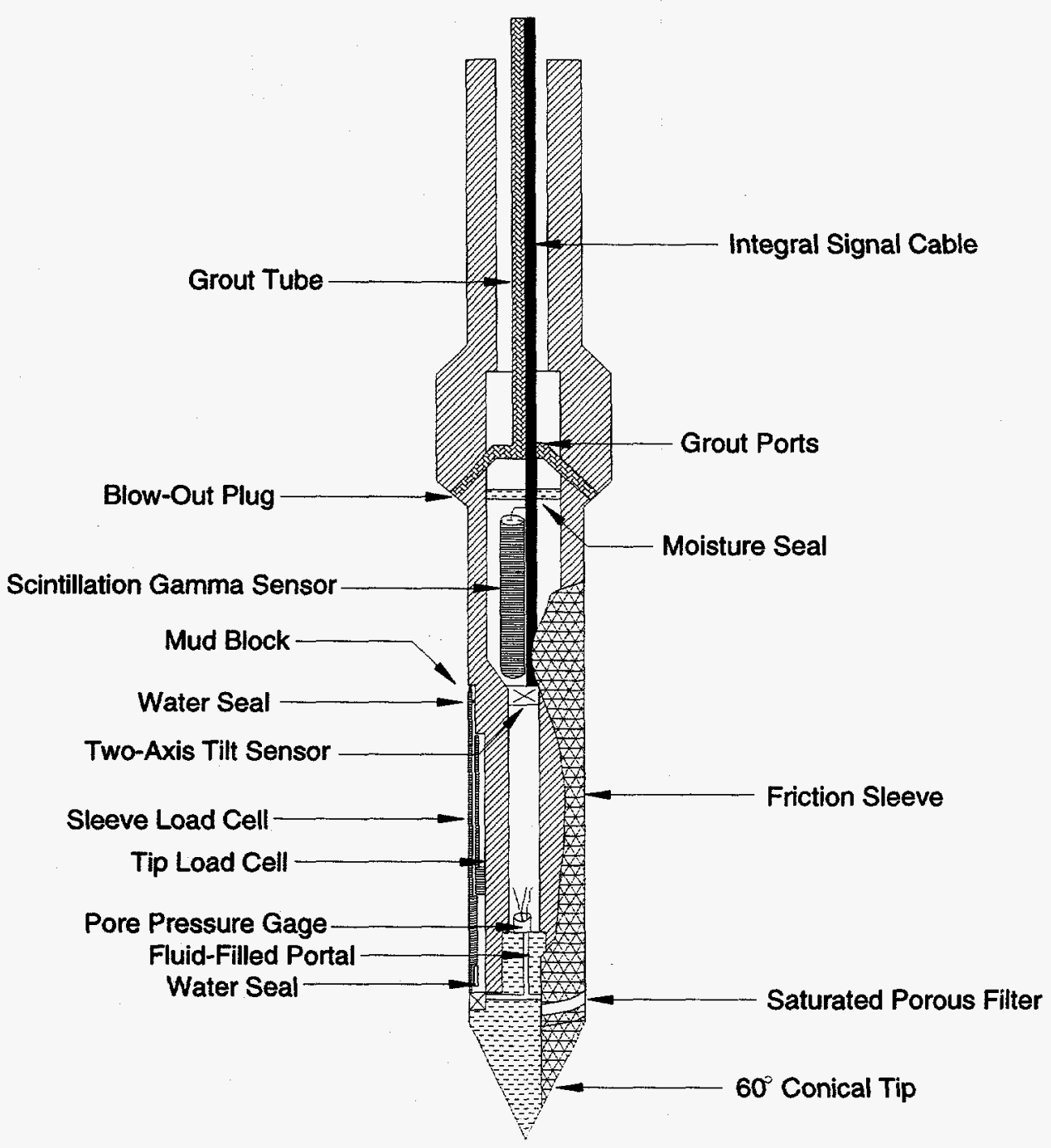

Schematic of a Radiation Detection Probe 


\section{APPENDIX B}

\section{REFERENCES}

1. Cespedes, E.R., S.R. Cooper, and W.M. Davis, 1994, In Situ Detection of TNT Contamination Using Electrochemical Sensors in Cone Penetrometer System, Optical Sensors for Environmental and Chemical Process Monitoring, Proceedings of Society of Photo-Optical Instrumentation Engineers, McLean VA, Nov. 9-10, v.2367, p. 33-42.

2. Advanced Sciences, Inc., 1994, Review of Instrumentation and Sensors Cone Penetrometer Applications Task 6 Report; DOE/HWP-149.

3. Lieberman, S., T. Hampton, D. Knowles, M. Davey, and W. McGinnis, 1995, Comparison of in situ laser-induced fluorescence (LIF) measurements of petroleum hydrocarbons in soils with conventional laboratory measurements. Abstract of 10th Annual Conference on Contaminated Soils, Amherst, MA.

4. Applied Research Associates, Inc., 1993, CPT-LIF Investigation of LUST Contamination at Tinker AFB, Oklahoma, Unpublished ARA Report.

5. Booth, S. R., C. J. Durepo, and D.L. Temet, 1993, Cost Effectiveness of the Cone Penetrometer Technology, Los Alamos National Laboratory Report, LA-UR-93-3383.

6. Schroeder, J.D., S.R. Booth, and L.K. Trocki, 1991, Cost Effectiveness of the Site Characterization and Analysis Penetrometer System, Los Alamos National Laboratory Report, LA-UR-91-4016.

7. Knowlton, R., W. Strong, J. Onsurez, and E. Rogoff, 1995, Advances in Hydrologic Measurement Techniques- In Situ and Cone Penetrometer Applications, SPIE Volume 2504, Environmental Monitoring and Hazardous Waste Site Remediation, Proceedings Europt Series, Munich FRG, June 1995.

8. Kyle, K., 1994, Conceptual Design of a Raman Probe for Inclusion in the In-tank Cone Penetrometer, Lawrence Livermore National Laboratory Report, UCRL-ID-118926.

9. Richterich, L.R. and B.R. Cassem, 1994, Cone Penetrometer Testing at the Hanford Site: Final Performance Evaluation Report, Westinghouse Hanford Company Report WHC-EP-0797.

10. Steedman, D., F. Seusy, J. Gibbons, and J. Bratton, 1993, Minimally Invasive Three-dimensional Site Characterization System, Argonne National Laboratory Report DOE/CH-9202.

11. Stromswold, D.C., J.E. Meisner, and W.G. Nicaise, 1994, CsI(Tl) with Photodiodes for Identifying Subsurface Radionuclide Contamination, Pacific Northwest Laboratory Report PNL-SA-24344.

12. Frye, G.C., R.W. Cernosek, T.D. Steinfort, D.W. Gilbert, and C. Colburn, 1994, Above-ground and In Situ Field Screening of VOCs Using Portable Acoustic Waste Sensor (PAWS) Systems, Sandia National Laboratory Report SAND-94-1916C. 